\title{
Investigating the Effect of Freshman Minority Engineering Student Partici- pation in a Minority Summer Bridge Program on Engineering Self-Efficacy and Early Academic Success at a Predominantly-White Institution
}

\author{
Dr. Javon Marcell Adams, North Carolina State University
}

Dr. Javon M. Adams is a Postdoctoral Research Associate in the College of Engineering at North Carolina State University (NCSU) focused on researching diversity Issues in Engineering. Dr. Adams graduated with his Ph.D. in Civil Engineering from NCSU in December 2014 after completing his dissertation which focused on Transportation Engineering Materials. During his time as an undergraduate and as a graduate student at NCSU, Dr. Adams actively participating in a wide range of efforts aimed at increasing the recruitment, retention, and advancement of minority student groups studying engineering on campus. These personal experiences fueled his desire to pursue research opportunities in the field of Diversity in Higher Education, specifically in STEM disciplines. During his time as a postdoctoral research, Dr. Adams has established the Minority Summer Research Program at NCSU and is conducting research related to various diversity issues on campus.

\section{Mr. James Samuel Carter III, University of North Carolina, Chapel Hill}

Mr. James Carter is a Ph.D. student in Education (Policy, Leadership, and School Improvement Strand). He holds undergraduate degrees in Aerospace Engineering and Sociology from North Carolina State University (2006). He worked at NAVAIR for 9 years before returning to school, most working as the Gas Turbine Compressor/Pneumatics Team Lead. 


\title{
Investigating the Effect of Freshman Minority Engineering Student Participation in a Minority Summer Bridge Program on Engineering Self-Efficacy and Early Academic Success at a Predominantly-White Institution
}

\begin{abstract}
Background
The broad moniker STEM (Science, Technology, Engineering, and Mathematics) is and continues to be, the focus of many in education and in industry. To maintain its position as a technological leader, the United States must not only continue to produce high-quality STEM field graduates but accelerate this production. The priority of this effort is revealed by President Barack Obama's push to produce an additional one million STEM graduates within a decade and an additional 100,000 new teachers in these fields (Feder, 2012). The sheer number of graduates required to fill the projected jobs in STEM fields will require both increasing the number of students entering these fields but also reducing the rate that college students exit these fields.
\end{abstract}

One of the keys to increasing the number of STEM professionals is to understand why students who start STEM degrees do not finish. Ohland et al. (2011) found that, of Black students who matriculate into engineering programs, the percentage of those who graduate within six years trails their White counterparts by 11 points. Since that time, Black students have increased their rate of going into engineering majors - they are at parity with White students in terms of their intentions to enter STEM fields - yet they lag in terms of degree completion (National Science Foundation, 2015, Table 2-8; National Science Foundation, 2015, Table 5-7).

Black males also underperform relative to their female counterparts in persistence to degree completion (Lord et al., 2009; National Science Foundation, 2015, Table 5-7). The discrepant graduation rate of black males is a problem, not only for equity but also for filling the number of open jobs in STEM. There is simply too much demand for STEM professionals in this country to have a degree completion rate issue with any given demographic.

The general persistence literature has illuminated many factors that affect student success in postsecondary education. Reason's (2009) excellent review of the literature lays out a framework for college persistence adapted from Terenzini and Reason (2005, Fig. 1). This framework takes into account "student precollege characteristics and experiences, the organizational context, the student peer environment, and, finally, the individual student experience" (Reason, 2009, p. 662). There are well-established differences in patterns of academic achievement and course-taking among incoming engineering students (Chang et al. 2014; Sass 2015; Tyson et al. 2007). These differences can express themselves as differences in the likelihood of academic success in college (Strayhorn, 2015). However, other studies have shown social psychological factors to be important in persistence as well (Brown et al., 2008; Reason, 2009).

One of these factors is self-efficacy. Self-efficacy beliefs are believed to influence choice of activity, effort in that activity, and persistence/perseverance during the activity (Lent, Brown, \& Hackett, 1994). In the persistence literature, self-efficacy is used as a predictor or mediator of academic success (Gloria \& Hird, 1999; Reid, 2013; Rice, Barth, Guadagno, Smith, \& 
McCallum, 2013). Given these encouraging results, interventions that impact the self-efficacy of students, particularly minority students, should positively impact persistence and ultimately degree completion. This study will look at the effect of one such intervention on self-efficacy in the form of a summer transition program (STP).

STP is a six-week residential bridge program for admitted under-represented minority (URM) freshman that targets retention of students from URM groups who have been poorly retained historically in engineering majors when compared to their majority counterparts. Participants in the STP program enroll in a college math course (for a grade) based on their university math placement exam score in the second summer session prior to the fall of their freshmen year. STP participants are enrolled in the same math sections to increase the feeling of community in and out of the classroom. Additionally, students attend mandatory math workshops and nightly study sessions to ensure students develop effective time management skills and study habits early in their collegiate careers.

This paper details a study into the self-efficacy beliefs and pre-college academic preparedness (i.e. high school GPA and SAT score) for two cohorts of URM students enrolled in the FirstYear Engineering Program at a predominantly white four-year research university. The study includes URM freshmen who participated in a summer transition program (STP) as well as URM freshmen who did not participate in the program from the same cohorts. The study investigates the relationship between self-efficacy, pre-college academic preparedness measures and the effect of these factors on early college success outcomes (e.g., term GPA) for URM students who participated in STP as well as URM students who did not participate.

\section{LITERATURE REVIEW}

Self-efficacy is defined as confidence in one's ability to perform specific tasks or courses of action necessary to attain a specific goal or function in a specific capacity. (Bandura, 1997). When measuring self-efficacy respondents are asked to rate their level of confidence for attaining a specific goal. A student's self-efficacy has an influence on the decisions that he/she makes regarding their demonstrated efforts to reach a certain goal choice, as well as their persistence towards that goal when faced with adversity (Bandura, 1997; Pajares, 2005).

Several studies investigated the role of self-efficacy beliefs as predictors of performance outcomes in science and engineering. These studies found that self-efficacy can account for variance in college outcomes (e.g., academic performance and persistence) beyond the variance that can be accounted for due to standardized achievement test scores and aptitude measures (Brown, Lent, \& Larkin, 1989; Lent, Brown, \& Larkin, 1986). Multon, Brown, and Lent (1991) conducted an analysis that found between $11 \%$ and $14 \%$ of the variance in academic performance and retention could be accounted for by a student's self-efficacy beliefs. In fact, Bandura and Locke (2003) found that self-efficacy positively predicts performance beyond prior performance and ability. Higher self-efficacy is related to students taking on more challenging goals and greater dedication towards those goals. Additionally, whether students' reaction to any gap in achievement between their expected and actual performance is to feel discouraged, or motivated, is driven by that student's self-efficacy (Rittmayer \& Beier, 2009). This importance is magnified in the pursuit of longer-term goals such as obtaining an engineering degree. Self- 
efficacy is essential as students are faced with short-term challenges such as a math or physics test along the path to the long-term goal of graduation. These short-term goals allow students the opportunity to demonstrate mastery of specific tasks incrementally which helps increase selfefficacy over time.

The importance of non-academic factors on college success outcomes should not be underestimated. Robbins et al. (2004) conducted a comprehensive review of research on the topic of postsecondary retention where over 109 studies were identified that examined the relationship between academic and non-academic factors and retention for full-time students enrolled in four-year postsecondary institutions. The researchers used a meta-analysis technique to identify which non-academic factors had the most significant relationship to college retention to indicate student dropout risk (Robbins et al. 2004). From this review, high school GPA and standardized test scores were identified as the academic factors most related to retention; while level of academic self-confidence, academic-related skills (e.g., study skills, note taking, using resources, etc.) social engagement and institutional support were among the most critical nonacademic factors. Lotkowski et al. (2004) found that non-academic factors such as academic confidence, social engagement, and support had a positive relationship to college retention. Academic confidence had the strongest relationship to college GPA among the non-academic factors according to Lotkowski. However, the overall relationship with college retention was strongest when academic preparedness measures (i.e., high school GPA and SAT/ACT scores) and non-academic factors (e.g., academic self-efficacy, social engagement etc.) were combined. The study also found that high school GPA and academic-related skills more strongly correlated to retention than to college GPA; while standardized test scores (i.e. SAT/ACT), self-efficacy belief, and achievement motivation had a stronger correlation to college GPA than to retention. Lotkowski advised that retention programs whose approach to retention solely utilizes precollege academic measures to identify at-risk students miss students who may become at-risk due to other non-academic factors (Lotkowski et al, 2004).

Brown et al. (2008) built upon the work of Robbins et al. (2004) by investigating whether psychosocial factors predict college outcomes. The study used a combination of meta-analytic and structural modeling methods to develop input correlation matrices for path analytical tests of the Social Cognitive Career Theory (SCCT) academic performance model developed by Lent, Brown, and Hackett (1994). SCCT seeks to predict how academic interests are formed and the means by which academic performance is achieved. College GPA and retention were used as performance criterion in the model. SCCT is based on the premise that general cognitive talent (i.e. academic preparedness), as represented by a students' standardized test scores and high school GPA, impacts college GPA and retention. This is shown in Brown's study to happen both directly and indirectly via mediating paths through a student's self-efficacy and expected academic outcomes. Brown observed two key findings that should be noted here. First, the researchers found that high school performance measures (i.e. GPA) appeared to have a more significant contribution towards predicting a student's self-efficacy beliefs than academic aptitude measured by standardized test scores $(\mathrm{z}=15.16, \mathrm{p}<.001)$. Though students' standardized test scores were found to have a greater direct correlation with college GPA than high school GPA ( $\mathrm{z}=2.14, \mathrm{p}=0.032)$. In the SCCT academic performance model, standardized path coefficients revealed SAT/ACT score and high school GPA have a weaker direct effect on college GPA, though these pre-college academic measures do have an indirect effect when 
combined with self-efficacy beliefs and academic goal-oriented behavior. This finding is important to note as it suggests that more academically talented students are no more likely to succeed in college than those with less academic aptitude without developing self-efficacy regarding their academic capabilities to succeed at the college level. This paper will investigate whether similar observations can be made specifically for minority students enrolled in engineering majors at PWIs by investigating the relationships between students' pre-college academic preparedness, self-efficacy beliefs, and collegiate academic performance. Brown's study concluded that without accounting for the non-academic factors found to be critical to college success in existing literature (Robbins 2004), pre-college academic preparedness is not an effective predictor of college success outcomes. Therefore, as engineering research universities rely heavily on pre-college academic preparedness measures (e.g., high school GPA and standardized test scores) in admissions decisions, it is of equal importance to employ programmatic efforts and support structures that can help students increase their self-efficacy beliefs in order to improve the likelihood of successful outcomes. One such programmatic effort that helps to instill academic confidence in students is the summer transition program (STP) which helps transition students from high school to college. This paper sought to investigate the impact of participation in STP on the self-efficacy beliefs of underrepresented minority students enrolled in engineering at a predominately white institution (PWI).

Among existing literature investigating the impact of summer bridge programs on college success outcomes for minority students enrolled in engineering majors at PWIs, one similar study was identified that is important to highlight here. Tomasko et al. (2016) conducted a longitudinal study of four cohorts of URM students enrolled in a summer bridge program for engineering students at a research-intensive land grant PWI of comparable size and demographic makeup to the institution studied in this paper. Tomasko's study sought to determine if participation in the summer bridge program improved retention in the STEM discipline among URM groups, as well as women and first-generation college students. The study also assessed non-academic factors such as the student's preparedness for entry into a STEM major and sense of belonging at the conclusion of the program. Ultimately, Tomasko found that the summer bridge program's URM participants had higher third-year retention rates in their STEM discipline than the general population of students admitted to STEM majors at the same university. The authors note that third year retention rates were utilized due to a lack of data for the cohorts beyond the third year of college. Tomasko rationalized this approach based on their findings that third-year retention rate was a good indicator of six-year graduation rates, as exhibited by just a 3-4\% difference in those rates. Cohort 1 demonstrated small retention improvements in retention over the general population while cohorts 2-4 showed an improvement of $8-10 \%$ retention for URM participants. Tomasko attributed these results to improved academic preparation, sense of belonging, and social support. Regarding the effectiveness of summer bridge programs, Suzuki et al. (2012) also found that students were more academically prepared and have a heightened sense of belonging following their experience in a summer bridge program. While Tomasko's study focused on comparisons of the URM group to the majority, the research effort detailed in this paper sought to more directly identify if URM students who participated in the STP bridge program showed any qualitative differences when compared against URM students who did not participate in the STP program. 


\section{METHODOLOGY}

\section{Survey Instrument}

The data collection instrument utilized for this study was the Longitudinal Assessment of Engineering Self-Efficacy (LAESE) survey (Marra and Bogue, 2006). The LAESE survey is a tested and validated instrument designed during a National Science Foundation (NSF) study to develop, test, and analyze assessment tools for measuring the self-efficacy of undergraduate students studying engineering (Marra et al., 2004; Marra et al., 2005; Marra and Bogue, 2006). Marra and Bogue (2006) found that to construct a self-efficacy instrument one must survey respondents feeling of efficaciousness in a very specific context related to the traditional barriers that separate a respondent from their goal or successful outcomes. Marra and Bogue developed a survey using items adapted from previous developmental work by Blaisdell (2000) and Betz and Hackett (1981) and tested it to ensure it was both valid and reliable. Results of the validity and reliability testing demonstrated that the survey instrument measured a variety of factors related to a student's self-efficacy. Statistical analysis conducted by the developers reported Cronbach's Alpha reliability coefficients that were deemed acceptable (Marra and Bogue 2006). The number of survey items and alpha coefficients for each subscale included in the survey is provided:

1. Engineering career expectations $(7$ items, alpha $=.84)$

2. Engineering self-efficacy I $(5$ items, alpha $=.82)$

3. Engineering self-efficacy II (6 items, alpha $=.82)$

4. Feeling of inclusion (4 items, alpha $=.73$ )

5. Coping self-efficacy (6 items, alpha $=.78)$

6. Math outcomes efficacy $(3$ items, alpha $=.84)$

Provided below are samples of questions from each of the six subscales in the LAESE survey instrument used in this research:

- Engineering career expectations

- Someone like me can succeed in an engineering career.

- A degree in engineering will allow me to get a job where I can use my talents and creativity.

- Engineering self-efficacy I

- I can succeed in an engineering curriculum.

- I can succeed in an engineering curriculum without having to give up. participation in my outside interests (e.g. extracurricular activities, family, sports)

$\circ$ I will succeed in my math courses.

- Engineering self-efficacy II

$\circ$ I can complete the math requirements for most engineering majors.

I can complete any engineering degree at this institution.

- Feeling of inclusion

- I can relate to the people around me in my class.

$\circ$ I have a lot in common with the other students in my classes.

- Coping self-efficacy

- I can cope with not doing well on a test. 
- I can make friends with people of different backgrounds and/or values.

- Math outcomes efficacy

○ Doing well at math will enhance my career/job opportunities

$\circ$ Doing well at math will increase my sense of self-worth.

The difference between engineering self-efficacy I and II should be clarified here. The main difference between the engineering self-efficacy I and II subscale items are that the items are phrased differently. Engineering self-efficacy subscale 1 items are phrased as "I can succeed (earn an A or B) in my engineering courses" (or math courses, or engineering curriculum) whereas the second engineering subscale asks students about their confidence in completing required portions of an engineering degree (e.g. "I can complete the physics requirements for most engineering majors"). The items in the coping self-efficacy subscale indicate that students feel more competent in being able to take positive actions to cope with potentially difficult or socalled "barrier" situations, such as doing poorly on an exam or adjusting to a new campus environment. Though students were given the entire survey, items from the self-efficacy I, selfefficacy II, and coping self-efficacy subscales were the focus of this study.

The LAESE instrument was used to measure changes in self-efficacy over time and between similar groups of students. While it was developed to measure changes in self-efficacy among women enrolled in engineering, the instrument can be used to measure self-efficacy of any group of engineering students (e.g., minority students) as prior research has demonstrated that selfefficacy can vary by race/ethnicity (Graham 1994). The LAESE instrument was utilized in the research detailed herein to investigate the self-efficacy beliefs of URM engineering students at a PWI.

\section{Data}

Data for this study come from two sources: Administration of the LAESE instrument and the University's student database. The LAESE survey responses were compiled into each of the six subscales per (Marra and Bogue, 2006) by taking the mean of the numeric responses (0-6, from 0 being "Strongly Disagree" or "Very Unimportant" to 6 being "Strongly Agree" or "Very Important") from each question in the subscale to obtain a subscale value for each student. If a student did not answer all the questions required to calculate a subscale, that student was not assigned a value for the subscale. As such, there is variation in the number of subjects included in each model. The analysis here is restricted to the subscales 2, 3 and 6 . The subscale values for each student are displayed as standardized (Z-score).

SAT scores and high school GPAs were collected for all the students in each cohort, as well as each student's first semester postsecondary GPA and demographic data from the University's student database.

\section{Subjects}

The participants in STP are incoming freshmen engineering students for each respective fall semester (2015 or 2016). The LAESE instrument was administered to most of the underrepresented minority students in the College of Engineering during the fall of their freshmen year. Of 143 minority students enrolled in 2015, the survey was given to 109 of them. In 2016, the survey was given to 104 of 149 minority freshmen who enrolled in Engineering. All 
the students whose responses make up the LAESE survey data are identified in the university data system as underrepresented minorities: Black or African-American, Non-White Hispanic, Native American/Alaska Native, Pacific Islander or Multiracial with at least one of the aforementioned groups as one of their group identifications.

\section{RESULTS}

\section{Group Comparisons}

First, the students who did not attend STP (comparison group) were compared to the students who did attend STP (treatment group) on observable pre-college indicators of academic preparedness for both the 2015 and 2016 cohorts. T-tests for group mean differences summarized in Table 1 showed no statistically significant difference in mean SAT scores for math or mean weighted high school GPA between the two groups. Next, the data were compared by gender as shown in Table 2. The male students had a higher mean math SAT score than the female students, but the female students had higher mean high school GPA. These results were significant for the combined sample and the comparison group for math SAT score and the treatment group for high school GPA. Table 3 shows the differences between the academic preparedness measures by cohort. The 2016 cohort mean high school GPA is higher than the 2015 cohort. This difference is statistically significant and driven largely by the 0.24 GPA difference among female students.

Table 1. Results of T-tests for Observable Pre-College Indicators of Academic Preparedness for the Comparison and Treatment Groups

\begin{tabular}{|c|c|c|c|c|}
\hline Count & \multicolumn{1}{|c|}{ Total } & Comparison & Treatment & p-value \\
\hline mathsat, mean (sd) & 213 & 156 & 57 & \\
\hline hsgpa, mean (sd) & $687(55.6)$ & $648(54.8)$ & $635(50.4)$ & 0.151 \\
\hline
\end{tabular}

Table 2. Results for T-tests of Observable Differences between Male and Female Students for the Comparison and Treatment Groups

\begin{tabular}{|l|l|r|r|r|c|}
\hline Math SAT & & \multicolumn{1}{c|}{ Total } & \multicolumn{1}{c|}{ Male } & \multicolumn{1}{c|}{ Female } & p-value \\
\hline & Comparison & $645(53.8)$ & $654(50.2)$ & $627(55.8)$ & 0.002 \\
\hline & Treatment & $635(54.8)$ & $659(49.4)$ & $628(59.1)$ & 0.003 \\
\hline HS GPA & & $4.59(0.307)$ & $641(51.0)$ & $626(49.3)$ & 0.313 \\
\hline & Comparison & $4.59(0.312)$ & $4.59(0.319)$ & $4.63(0.280)$ & 0.14 \\
\hline & Treatment & $4.57(0.297)$ & $4.48(0.276)$ & $4.59(0.276)$ & 0.917 \\
\hline
\end{tabular}


Table 3. T-test for Differences in Means by Cohort

\begin{tabular}{|l|c|c|r|r|c|}
\hline \multicolumn{2}{l|}{} & \multicolumn{1}{c|}{ Total } & \multicolumn{1}{c|}{$\mathbf{2 0 1 5}$} & \multicolumn{1}{c|}{$\mathbf{2 0 1 6}$} & p-value \\
\hline Math SAT & & $645(53.8)$ & $646(54.0)$ & $643(53.8)$ & 0.72 \\
\hline & Male & $654(50.2)$ & $652(54.3)$ & $658(44.9)$ & 0.549 \\
\hline & Female & $627(55.8)$ & $633(52.1)$ & $622(59.0)$ & 0.452 \\
\hline HS GPA & & $4.59(0.307)$ & $4.52(0.276)$ & $4.66(0.327)$ & 0.003 \\
\hline & Male & $4.56(0.319)$ & $4.53(0.278)$ & $4.60(0.369)$ & 0.246 \\
\hline & Female & $4.63(0.280)$ & $4.50(0.276)$ & $4.74(0.236)$ & 0 \\
\hline
\end{tabular}

The least squares regression models for analysis are of the general form:

$$
Y_{i}=\alpha+\beta(\text { Summer Bridge })+\gamma(\text { Controls })+\partial(\text { Other Indicators })+\varepsilon
$$

The controls, Math SAT score and high school GPA, come from the University's student database. High school GPA is the students' weighted GPA. The other indicator variables are 'cohort' and 'female'. 'Cohort' is a dichotomous variable where zero indicates the 2015 cohort and one indicates the 2016 cohort. 'Female' is similarly coded zero for male and one for female.

Table 4 shows the effect of the treatment (i.e. STP attendance) for each of the outcome variables of interest: Engineering Self-Efficacy I, Engineering Self-Efficacy II, Coping Self-Efficacy and First Semester First Year GPA. The base models show statistically significant effects for Engineering Self-Efficacy I (subscale 2) and Coping Self-Efficacy (subscale 5) with coefficients of 0.369 and 0.400 standard deviations respectively. Table 5 shows the same outcome variables with the precollege academic preparedness controls. Controlling for Math SAT score and High School GPA, Engineering Self-Efficacy II (subscale 3) also becomes statistically significant with a coefficient of 0.352 . Math SAT score coefficients were statistically significant for each subscale, but two orders of magnitude smaller than the coefficients for the treatment ( 0.003 and 0.005 standard deviation increases in Engineering Self-Efficacy I and II, respectively). This magnitude difference is not unexpected, as the coefficient for math SAT corresponds to the change in an outcome variable associated with a 1-point increase in math SAT score. High School GPA was the only significant coefficient for Fall GPA but was the largest predictor of any of the variables in any of the models.

Table 6 shows the full models with the indicator variables for 'cohort' and 'female'. None of the indicator variable coefficients are statistically significant and the other coefficients do not change much. White tests for heteroscedasticity were performed on all models with no tests rejecting the null hypothesis for homoscedasticity for any model. 
Table 4. Effect of Treatment for Each of the Outcome Variables of Interest

\begin{tabular}{|c|c|c|c|c|}
\hline & ESE I & $\begin{array}{l}\text { ESE } \\
\text { II }\end{array}$ & $\begin{array}{l}\text { Coping } \\
\text { SE }\end{array}$ & $\begin{array}{l}1 \text { st } \\
\text { Semester } \\
\text { GPA }\end{array}$ \\
\hline & $\mathrm{b} / \mathrm{se} / \mathrm{p}$ & $\mathrm{b} / \mathrm{se} / \mathrm{p}$ & $\mathrm{b} / \mathrm{se} / \mathrm{p}$ & $\mathrm{b} / \mathrm{se} / \mathrm{p}$ \\
\hline \multirow[t]{3}{*}{ Treatment } & $0.369 * *$ & 0.25 & $0.400 * *$ & -0.029 \\
\hline & 0.173 & 0.161 & 0.16 & 0.103 \\
\hline & 0.034 & 0.123 & 0.013 & 0.782 \\
\hline \multirow[t]{3}{*}{ Constant } & -0.095 & -0.07 & -0.103 & $3.255^{* * *}$ \\
\hline & 0.088 & 0.085 & 0.081 & 0.054 \\
\hline & 0.28 & 0.413 & 0.206 & 0 \\
\hline $\mathrm{N}$ & 171 & 189 & 197 & 204 \\
\hline $\mathrm{r} 2$ & 0.026 & 0.013 & 0.031 & 0 \\
\hline & & .0 & $F^{2}<0.0$ & \\
\hline
\end{tabular}

Table 5. Outcome Variables with the Precollege Academic Preparedness Controls

\begin{tabular}{|c|c|c|c|c|}
\hline & ESE I & ESE II & $\begin{array}{l}\text { Coping } \\
\text { Self- } \\
\text { Efficacy }\end{array}$ & $\begin{array}{l}1^{\text {st }} \\
\text { Semester } \\
\text { GPA }\end{array}$ \\
\hline & $\mathrm{b} / \mathrm{se} / \mathrm{p}$ & $\mathrm{b} / \mathrm{se} / \mathrm{p}$ & $\mathrm{b} / \mathrm{se} / \mathrm{p}$ & $\mathrm{b} / \mathrm{se} / \mathrm{p}$ \\
\hline \multirow[t]{3}{*}{ Treatment } & $0.460 * *$ & $0.352 *$ & $0.523 * * *$ & -0.001 \\
\hline & 0.187 & 0.184 & 0.176 & 0.106 \\
\hline & 0.016 & 0.058 & 0.003 & 0.993 \\
\hline \multirow[t]{3}{*}{ MathSAT } & $0.003^{* *}$ & $0.005 * * *$ & $0.004 * * *$ & 0.001 \\
\hline & 0.002 & 0.002 & 0.001 & 0.001 \\
\hline & 0.032 & 0.002 & 0.005 & 0.186 \\
\hline \multirow[t]{3}{*}{ HS GPA } & 0.429 & 0.177 & -0.212 & $0.751 * * *$ \\
\hline & 0.279 & 0.281 & 0.265 & 0.157 \\
\hline & 0.126 & 0.529 & 0.424 & 0 \\
\hline \multirow[t]{3}{*}{ Constant } & $-4.345^{* * *}$ & $-4.162 * * *$ & -1.874 & -0.981 \\
\hline & 1.47 & 1.491 & 1.395 & 0.853 \\
\hline & 0.004 & 0.006 & 0.181 & 0.252 \\
\hline $\mathrm{N}$ & 127 & 141 & 149 & 156 \\
\hline $\mathrm{r} 2$ & 0.094 & 0.089 & 0.097 & 0.154 \\
\hline & $* \mathrm{p}<10$ & $n<005$ & $* \mathrm{p}<0.01$ & \\
\hline
\end{tabular}


Table 6. Full Models with Indicator Variables for STP Cohort and Gender

\begin{tabular}{|l|l|l|l|l|}
\hline & ESE I & ESE II & $\begin{array}{l}\text { Coping } \\
\text { Self- } \\
\text { Efficacy }\end{array}$ & $\begin{array}{l}1^{\text {st }} \\
\text { Semester } \\
\text { GPA }\end{array}$ \\
\hline & $\mathrm{b} / \mathrm{se} / \mathrm{p}$ & $\mathrm{b} / \mathrm{se} / \mathrm{p}$ & $\mathrm{b} / \mathrm{se} / \mathrm{p}$ & $\mathrm{b} / \mathrm{se} / \mathrm{p}$ \\
\hline Treatment & $0.460^{* *}$ & $0.350^{*}$ & $0.531^{* * *}$ & -0.018 \\
\hline & 0.189 & 0.185 & 0.178 & 0.107 \\
\hline & 0.016 & 0.061 & 0.003 & 0.863 \\
\hline MathSAT & $0.003^{* *}$ & $0.005^{* * *}$ & $0.004^{* *}$ & 0.001 \\
\hline & 0.002 & 0.002 & 0.002 & 0.001 \\
\hline & 0.044 & 0.006 & 0.013 & 0.174 \\
\hline HS GPA & 0.399 & 0.233 & -0.191 & $0.781^{* * *}$ \\
\hline & 0.298 & 0.302 & 0.285 & 0.166 \\
\hline & 0.184 & 0.441 & 0.505 & 0 \\
\hline Cohort & 0.079 & -0.053 & 0.013 & -0.11 \\
\hline & 0.176 & 0.179 & 0.169 & 0.102 \\
\hline & 0.653 & 0.768 & 0.937 & 0.281 \\
\hline Female & -0.039 & -0.09 & -0.106 & 0.073 \\
\hline & 0.185 & 0.184 & 0.173 & 0.107 \\
\hline & 0.835 & 0.624 & 0.539 & 0.492 \\
\hline Constant & - & - & -1.774 & -1.149 \\
& $4.183^{* * *}$ & $4.177 * * *$ & & \\
\hline & 1.516 & 1.515 & 1.432 & 0.865 \\
\hline & 0.007 & 0.007 & 0.217 & 0.186 \\
\hline & & & & \\
\hline $\mathrm{N}$ & 127 & 141 & 149 & 156 \\
\hline $\mathrm{r} 2$ & 0.096 & 0.091 & 0.099 & 0.162 \\
\hline & & & & \\
\hline & $* \mathrm{p}<.10, * * \mathrm{p}<0.05, * * * \mathrm{p}<0.01$ & \\
\hline & & & & \\
\hline & & &
\end{tabular}

\section{Interactions}

Several models were run with different combinations of interaction terms between the independent variables (treatment dummy variable, math SAT score, high school GPA, the gender dummy variable, and the cohort dummy variable) and demographic characteristics of the students (gender and race). None of the interaction coefficients were statistically significant at the 0.1 level or below. Also, the statistical significance of the main effects disappeared when including the interaction terms in the models. Similarly, interacting the treatment dummy variable with dummy variables for gender and race did not yield significant coefficients on any outcome variables. As such, these models are omitted from the analysis presented here.

\section{DISCUSSION}

While the study design does not allow for causal claims, there appear to be real, observable 
differences in the students who attended the summer transition program and the URM students who did not, as measured by the subscales of the LAESE instrument that were analyzed: Engineering Self-Efficacy I, Engineering Self-Efficacy II, and Coping Self-Efficacy. The coefficients for the STP indicator variable are positive and statistically significant (ceteris paribus) for the engineering self-efficacy subscales. These coefficients are very large in magnitude when compared to those of Math SAT scores in the same models. The treatment effect of STP participation is equivalent to Math SAT score increases of 153, 70, and 131 points on the Engineering Self-Efficacy I, Engineering Self-Efficacy II, and Coping Self-Efficacy subscales, respectively. There was no statistically significant effect for STP on Fall GPA. The coefficients for gender and cohort are also not statistically significant, indicating no increase in any of the outcome variables due to gender or cohort differences and further supporting the decision to pool the participants into one sample.

As expected from the literature, math SAT scores have a positive correlation with increased selfefficacy in the subscales analyzed and high school GPA correlates positively with first semester GPA. The high school GPA coefficients in the Fall GPA models are consistently the largest coefficients and the smallest p-values of any of the models. Math SAT scores positively affect the self-efficacy scales at a rate of about one-third to one-half of a standard deviation increase per 100-point increase in math SAT.

Since none of the models that included interaction terms contained significant coefficients, it can be assumed that the coefficients in the main effects for each model are not contingent upon treatment. This finding is especially important for the race and gender interaction terms as the impact of attending STP can be considered homogenous across the different intersectional identities of the underrepresented minority students that are invited to STP. It is also noteworthy that the interaction between the treatment dummy variable and the cohort dummy variable is non-significant. This indicates the treatment is stable over time.

\section{Limitations}

A few limitations are noted in this study. First, the assignment is non-random so the unobserved variation between the students who enroll in STP and those who do not could be associated with differences in scores on the subscales. This makes causal inference impossible but the comparatives are interesting nonetheless. A second limitation is the program was only run at one university so any effects from the setting are buried in the error term instead of available for analysis. Thirdly, generalizability is further restricted by the sample size (which is, itself, limited by the program size). That an effect is found with a small sample, and the associated lower statistical power, is encouraging.

\section{CONCLUSIONS}

The study investigated the impact of participation in STP on academic performance and retention among underrepresented minority students enrolled in engineering at a PWI. The STP participation is correlated with an improvement in engineering self-efficacy for the 2015 cohort. The STP coefficients are very large compared to Math SAT score in terms of its effect on engineering self-efficacy, though Math SAT is significant - as expected - for engineering selfefficacy. 
HSGPA is nearly significant for coping self-efficacy (relatively large negative coefficient) in 2015. Interestingly enough, STP participation wipes out that effect. This is a useful finding in that it shows that for URM participation in the summer transition program can help reduce the gap in self-efficacy, or lack of academic confidence, for students who achieved at lower levels of past achievement when compared with their peers. This might be attributed to the non-academic components of the STP experience such as improving student's feelings of inclusion through community building activities, learning through interaction with diverse role models at various stages of their engineering careers, an emphasis on study and time management skills, and oncampus resource awareness/utilization.

Another key finding is that there are observable differences in the students who attended STP and those who did not as measured by all the subscales of the LAESE instrument included in this analysis (i.e. Engineering Self-Efficacy I, Engineering Self-Efficacy II and Coping SelfEfficacy). The effect of participation in STP effectively equates to an approximately 70-130 pt. increase in math SAT score as it relates to self-efficacy. This demonstrates that participation in STP can have a positive effect on the self-efficacy beliefs of students which can increase retention of URM minority students which is a key goal of summer bridge programs.

It is also worth noting that no significant interaction terms or differences could be observed by race or gender. The program seems equally effective for all the intersectional identities covered by the moniker "underrepresented minority" as measured here.

However, the findings included herein do not demonstrate that participation in STP improves college GPA as STP participation was not found to be significant for first term GPA. High school GPA was positively correlated with 1st semester GPA (with large coefficients). Summer bridge programs like STP are likely not useful if academic performance in college is the key outcome but could be useful for retention. This is not to say that students in STP do worse than their peers, just that STP is not correlated with the differences observed in 1st semester GPA.

Instead of simply trying to find students with better SAT scores to help with retention rates, programs like STP can help keep the students that are admitted to a given institution in school and progressing towards a degree. 


\section{REFERENCES}

Bandura, A., \& Locke, E. A. (2003). Negative self-efficacy and goal effects revisited. Journal of applied psychology, 88(1), 87.

Brown, S. D., Lent, R. W., \& Larkin, K. C. (1989). Self-efficacy as a moderator of scholastic aptitude-academic performance relationships. Journal of vocational behavior, 35(1), 6475.

Brown, S. D., Tramayne, S., Hoxha, D., Telander, K., Fan, X., \& Lent, R. W. (2008). Social cognitive predictors of college students' academic performance and persistence: A metaanalytic path analysis. Journal of Vocational Behavior, 72(3), 298-308.

Chang, M. J., Sharkness, J., Hurtado, S., \& Newman, C. B. (2014). What matters in college for retaining aspiring scientists and engineers from underrepresented racial groups. Journal of Research in Science Teaching, 51(1), 555-580. doi:10.1002/tea.21146

Feder, M. (2012, December 18). One decade, one million more STEM graduates [Web log post]. Retrieved from https://obamawhitehouse.archives.gov/blog/2012/12/18/onedecade-one-million-more-stemgraduateshttps://obamawhitehouse.archives.gov/blog/2012/12/18/one-decade-onemillion-more-stem-graduates

Gloria, A. M., \& Hird, J. S. (1999). Influences of ethnic and nonethnic variables on the career decision-making self-efficacy of college students. The Career Development Quarterly, 48(2), 157-174.

Graham, S. (1994). Motivation in african americans. review of educational research, 64, 55 118.

Lent, R. W., Brown, S. D., \& Hackett, G. (1994). Toward a unifying social cognitive theory of career and academic interest, choice, and performance. Journal of Vocational Behavior, 45(1), 79-122. doi:10.1006/jvbe.1994.1027

Lent, R. W., Brown, S. D., \& Larkin, K. C. (1987). Comparison of three theoretically derived variables in predicting career and academic behavior: Self-efficacy, interest congruence, and consequence thinking. Journal of counseling psychology, 34(3), 293.

Lent, R. W., Miller, M. J., Smith, P. E., Watford, B. A., Lim, R. H.; Hui, K.; Williams, K. (2013). Social cognitive predictors of adjustment to engineering majors across gender and race/ethnicity. Journal of Vocational Behavior, 83(1), 22-30.

Lord, S. M., Camacho, M. M., Layton, R. A., Long, R. A., Ohland, M. W., \& Wasburn, M. H. (2009). Who's persisting in engineering? A comparative analysis of female and male asian, black, hispanic, native american, and white students. Journal of Women and Minorities in Science and Engineering, 15(2), 167-190. doi:10.1615/JWomenMinorScienEng.v15.i2.40

Lotkowski, V. A. Robbins. (2004). The Role of academic and non-academic factors in improving college retention. ACT Policy Report. Retrieved from https://eric.ed.gov/?id=ED485476

Marra, R. M., \& Bogue, B. (2006). Women engineering students self efficacy: a longitudinal multi-institution study. In Proceedings of the 2006 WEPAN Conference.

Marra, R. M., Moore, C., Schuurman, M., \& Bogue, B. (2004). Assessing women in engineering (AWE): assessment women engineering students' self-efficacy beliefs. Proceedings of 
the annual meeting of the Women Engineering Program Advocacy Network. June 6 - 9, Albuquerque, N.M. Available at http://www.xcd.com/wepan04/prof14.html.

Marra, R. M., Schuurman, M., Moore, C., \& Bogue, B. (2005). "Women engineering students' self-efficacy beliefs - The longitudinal picture". Proceedings of the annual meeting of the American Society for Engineering Education Annual Conference, 12 - 15 June, Portland, OR.

Multon, K. D., Brown, S. D., \& Lent, R. W. (1991). Relation of self-efficacy beliefs to academic outcomes: A meta-analytic investigation. Journal of Counseling Psychology, 38(1), 3038. https://doi.org/10.1037/0022-0167.38.1.30

National Science Foundation, National Center for Science and Engineering Statistics. (2015). Women, minorities, and persons with disabilities in science and engineering: 2015 (Special Report NSF 15-311). Retrieved from http://www.nsf.gov/statistics/2015/nsf15311/tables.cfmhttp://www.nsf.gov/statistics/2015 Insf15311/tables.cfm

Ohland, M. W., Brawner, C. E., Camacho, M. M., Layton, R. A., Long, R. A., Lord, S. M., \& Wasburn, M. H. (2011). Race, gender, and measures of success in engineering education. Journal of Engineering Education, 100(2), 225-252. doi:10.1002/j.21689830.2011.tb00012.x

Reason, R. D. (2009). An examination of persistence research through the lens of a comprehensive conceptual framework. Journal of College Student Development, 50(6), 659-682. doi:10.1353/csd.0.0098

Reid, K. W. (2013). Understanding the relationships among racial identity, self-efficacy, institutional integration and academic achievement of black males attending research universities. Journal of Negro Education, 82(1), 75-93. doi:10.7709/jnegroeducation.82.1.0075

Rice, L., Barth, J., Guadagno, R., Smith, G., \& McCallum, D. (2013). The role of social support in students' perceived abilities and attitudes toward math and science. Journal of Youth \& Adolescence, 42(7), 1028-1040. doi:10.1007/s10964-012-9801-8

Rittmayer, M.A. \& Beier, M.E. (2009). Self-efficacy in STEM. In B. Bogue \& E. Cady (Eds.). Applying Research to Practice (ARP) Resources. Retrieved <February 10, 2017> from http://www.engr.psu.edu/AWE/ARPresources.aspx

Robbins, S. B., Lauver, K., Le, H., Davis, D., Langley, R., \& Carlstrom, A. (2004). Do psychosocial and study skill factors predict college outcomes? A meta-analysis. Psychological Bulletin, 130(2), 261-288. https://doi.org/10.1037/0033-2909.130.2.261

Sass, T. (2015, January). Understanding the STEM pipeline (Working Paper 125). National Center for Analysis of Longitudinal Data in Educational Research: Washington, DC. Retrieved from http://files.eric.ed.gov/fulltext/ED560681.pdf

Suzuki, A., Amrein-Beardsley, A., \& Perry, N. (2012). A summer bridge program for underprepared first-year students: confidence, community, and re-enrollment. Journal of The First-Year Experience \& Students in Transition, 24(2), 85-106.

Strayhorn, T. L. (2015). Factors influencing black males' preparation for college and success in STEM majors: a mixed methods study. The Western Journal of Black Studies, 39(1), 4563.

Terenzini, P. T., \& Reason, R. D. (2005, November). Parsing the first year of college: a conceptual framework for studying college impacts. Paper presented at the meeting of the Association for the Study of Higher Education, Philadelphia, PA. 
Tomasko, D. L., Ridgway, J. S., Waller, R. J., \& Olesik, S. V. (2016). Association of summer bridge program outcomes with STEM retention of targeted demographic groups. Journal of College Science Teaching, 45(4), 90.

Tyson, W., Lee, R., Borman, K. M., \& Hanson, M. A. (2007). Science, technology, engineering, and mathematics (STEM) pathways: high school science and math coursework and postsecondary degree attainment. Journal of Education for Students Placed at Risk, 12(3), 243-270. doi:10.1080/10824660701601266 